\title{
Evaluación de la embriotoxicidad de misoprostol utilizando el ensayo cultivo de embriones postimplantación
}

\author{
CAROLINA CAMPOS E. ${ }^{1, a}$, M. FERNANDA CAVIERES ${ }^{1, a, b}$
}

\section{Evaluation of embryotoxicity of misoprostol using the whole embryo culture assay}

Background: Approximately 15\% of misoprostol-induced-abortions may not be successful, leading to in utero exposure to the drug and to the induction of a series of defects including central nervous system, limb and visceral defects. A common proposal is that the drug causes disruption of the fetal vasculature leading to embryonic or fetal hypoxia. Aim: To evaluate the teratogenicity of misoprostol using the rat postimplantation embryo culture. Material and Methods: Rat embryos were collected at the beginning of organogenesis and cultured in rat serum containing misoprostol at concentrations of 200, 2,000 or 20,000 pg/ml. Functionality, morphology and morphometry parameters were evaluated. Results: Misoprostol induced a dosedependent embryotoxic effect causing a decrease in embryo viability and function (poor vascular development and survival) and morphometry (alterations in branchial arches, heart and cephalic portions of the neural tube, among others). Conclusions: All the manifestations observed are indicative of the ability of misoprostol to directly induce developmental retardation and alterations.

(Rev Med Chile 2011; 139: 613-617).

Key words: Embryo culture techniques; Misoprostol; Teratology; Toxic potential.
${ }^{1}$ Facultad de Farmacia, Universidad de Valparaíso auímico Farmacéutico. bPhD, Toxicólogo.

Financiamiento: Proyecto DIPUV-REG 43/2006

Recibido el 15 de octubre de 2010, aceptado el 11 de abril de 2011.

Correspondencia a: María Fernanda Cavieres Facultad de Farmacia, Universidad de Valparaíso Av. Gran Bretaña 1093, Playa Ancha, Valparaíso Teléfono: 32-2508124 E-mail: fernanda.cavieres@ uv.cl
$\mathrm{M}$ isoprostol, un análogo sintético de la prostaglandina E1, es utilizado en Chile como citoprotector de la mucosa gástrica para prevenir úlceras inducidas por anti-inflamatorios no esteroidales. En otros países es también indicado para inducción de parto y de abortos. El uso de misoprostol como agente abortivo es considerado seguro dado que raramente causa efectos laterales serios o prolongados ${ }^{1}$. Sin embargo, aproximadamente $15 \%$ de los abortos inducidos por este medicamento fallan, llevando a una exposición in utero a la droga ${ }^{2}$.

El misoprostol pertenece a la categoría X de la Food and Drugs Administration (FDA) de los Estados Unidos de Norteamérica, dado que puede causar artrogriposis, defectos de extremidades, anormalidades cerebrales, gastrosquisis y síndrome de Moebius ${ }^{3}$. Este espectro de defectos fue descrito por primera vez en Brasil durante la década de 1980-89 y actualmente se reconoce una fuerte asociación epidemiológica entre la exposición al medicamento durante la gestación y la inducción de defectos del desarrollo ${ }^{4}$. El mecanismo que media esta toxicidad no ha sido dilucidado todavía. Sin embargo, dada la similitud entre los defectos observados en niños expuestos al misoprostol y aquellos defectos inducidos por hipoxia, se ha propuesto que el medicamento causa una disrupción de la vasculatura fetal en una etapa del desarrollo altamente dependiente de oxígeno. Esta disrupción podría ser causada por las contracciones uterinas que atrapan la sangre fetal en la placenta ${ }^{5}$ o por vasoconstricción de las arterias uterinas disminuyendo el flujo sanguíneo fetal ${ }^{6}$. Una de las consecuencias de la hipoxia sería la alteración del desarrollo de los nervios cranea- 
nos, lo cual llevaría a la parálisis de los músculos faciales en el síndrome de Moebius.

Prácticamente no existen en la literatura científica publicaciones que informen sobre el uso de modelos animales para estudiar la teratogenicidad del misoprostol. Sin embargo, Kotsonis $\mathrm{y} \mathrm{col}^{7}$ informaron sobre los estudios de toxicidad realizados mientras el medicamento fue desarrollado. Interesantemente, en estos estudios, la fetotoxicidad y la teratogenicidad en ratas a dosis orales de hasta $10.000 \mu \mathrm{g} / \mathrm{kg}$ o en conejos en dosis de hasta $1.000 \mu \mathrm{g} / \mathrm{kg}$ fueron negativos, aunque se observaron resorciones en un conejo y en una rata. Por otro lado, Paumgarten $\mathrm{y} \mathrm{col}^{8}$ señalan que no se encontró evidencia de embriotoxicidad a $20 \mathrm{mg} / \mathrm{kg}$ cuando el medicamento se administró a ratonas preñadas en el día 10 de gestación. De esta forma, se podría suponer que los ensayos in vivo usualmente utilizados para estudiar toxicidad del desarrollo no son adecuados para modelar el efecto de misoprostol en humanos.

El objetivo principal de este trabajo es estudiar la toxicidad de misoprostol sobre la gestación utilizando el ensayo in vitro cultivo de embriones de rata post-implantación, con el fin de evaluar un nuevo modelo experimental que permita conocer con más detalles el mecanismo de acción que media la teratogenicidad del medicamento.

\section{Materiales y Métodos}

\section{Animales de experimentación}

Se utilizaron ratas Sprague Dawley de 8 a 12 semanas de edad y de $250 \pm 30 \mathrm{~g}$ de peso aproximadamente. Los animales fueron mantenidos a temperatura de $21^{\circ} \mathrm{C}$, ciclos de luz/oscuridad (12/12) y acceso a alimento (Lab Rat, Champion) y agua ad libitum. Para la obtención de embriones, los machos fueron cruzados con las hembras en proporción 1:3, durante un período de cruza de 17:00 PM a 9:00 AM. La detección de espermios en un frotis vaginal luego de la cruza indicaba día de gestación 0,5 . Todos los procedimientos con animales de experimentación se basaron en las normas Guide for the Care and Use of Laboratory Animals del National Research Council $^{9}$ de los Estados Unidos de Norteamérica y contaron con la aprobación del Comité de Ética de la Facultad de Farmacia de la Universidad de Valparaíso.

\section{Cultivo de embriones}

Se utilizó el procedimiento del Centro Europeo para la Validación de Métodos Alternativos, ECVAM. Los embriones (10 por tratamiento), de edad gestacional 9,5 días fueron recolectados por cesárea y fueron cultivados en tubos desechables de $15 \mathrm{ml}$ a $37^{\circ} \mathrm{C}$ por 48 horas, en solución salina Hanks, $\left(\mathrm{CaCl}_{2}, \mathrm{NaCl}, \mathrm{KCl}, \mathrm{MgSO}_{4}, \mathrm{NaHCO}_{3}\right.$, glucosa, $\mathrm{Na}_{2} \mathrm{HPO}_{4}$ y $\mathrm{KH}_{2} \mathrm{PO}_{4}$ ), suero de rata, misoprostol (Sigma) y con mezcla variable de $\mathrm{O}_{2}, \mathrm{~N}_{2}$ y $\mathrm{CO}_{2}$, según tiempo de cultivo. Los tubos fueron puestos sobre un agitador rotatorio a $60 \mathrm{rpm}$ quedando en posición inclinada para favorecer el intercambio de nutrientes. Cada tubo contenía máximo 4 embriones siendo el volumen total del medio de cultivo de $4 \mathrm{ml}$. Debido a que misoprostol es un compuesto liposoluble, se utilizó formamida desionizada (Sigma) en una concentración de 0,5\% como vehículo. Los embriones recolectados fueron aleatoriamente asignados a 5 tratamientos: control sin misoprostol, control de vehículo y concentraciones crecientes de misoprostol (200, 2.000 y $20.000 \mathrm{pg} / \mathrm{ml})$, siendo alrededor de $200 \mathrm{pg} / \mathrm{ml}$ la concentración plasmática de ácido misoprostóico, (metabolito activo del misoprostol) que se alcanza en una mujer a la que se ha administrado una dosis de $400 \mu \mathrm{g}$ del medicamento vía vaginal ${ }^{10,11}$. Adicionalmente, para evaluar la dosis-dependencia de la toxicidad se ensayaron dos concentraciones más altas.

\section{Evaluación de embriotoxicidad}

$\mathrm{Al}$ término del cultivo, cada embrión fue evaluado con parámetros de crecimiento: diámetro del saco embrionario, longitud cráneo-nalga y longitud de la cabeza y se observó funcionalidad a través de presencia de latido cardiaco y de circulación en el saco embrionario y alantoides. Se realizó también una evaluación morfológica y morfométrica para establecer embriotoxicidad según Brown y Fabro ${ }^{12}$. De esta manera, para cada embrión se calculó un Puntaje Morfológico Total, el cual consistió en la observación del estado de desarrollo de saco embrionario, alantoides, rotación embrionaria, corazón, barras braquiales, tubo neural, sistema ótico, sistema óptico, sistema olfatorio, maxilar, mandíbula, romboencéfalo, mesencéfalo, prosencéfalo, extremidades anteriores y extremidades posteriores, asignándose, a cada uno, un puntaje de 0 a 5 ó 6 , según el estado de desarrollo de cada una de las estructuras, siendo 0 
no hay desarrollo y 5 ó 6, desarrollo normal para la etapa gestacional. La sumatoria de todos estos puntajes es el Puntaje Morfológico Total.

\section{Análisis Estadístico}

Para determinar el efecto del misoprostol sobre los parámetros de crecimiento, se aplicó análisis de varianza ANOVA $(\mathrm{p}<0,01)$, utilizándose el programa estadístico Graph Pad Prism 5.

\section{Resultados}

El misoprostol fue ensayado en el cultivo de embriones de rata postimplantación en tres concentraciones crecientes: 200, 2.000 y 20.000 $\mathrm{pg} / \mathrm{ml}$ de medio de cultivo, siendo $200 \mathrm{pg} / \mathrm{ml} \mathrm{la}$ concentración plasmática máxima que ha sido informada en mujeres a las que se ha administrado $400 \mu \mathrm{g}$ del medicamento por vía intravaginal. Adicionalmente se cultivaron embriones en medio de cultivo sin misoprostol y en medio de cultivo más formamida (vehículo del medicamento).

La Tabla 1 muestra el efecto de los tratamientos sobre el desarrollo embrionario. El misoprostol indujo un efecto embriotóxico dosis-dependiente disminuyendo también la viabilidad de los embriones a $20.000 \mathrm{pg} / \mathrm{ml}$. Todos los parámetros evaluados: diámetro del saco embrionario, longitud cráneo-nalga, longitud de cabeza y puntaje morfológico total disminuyeron significativamente al aumentar la dosis de misoprostol, en comparación con los controles sin misoprostol y con formamida $(\mathrm{p}<0,0001)$.
Específicamente, los marcadores del desarrollo utilizados para tabular el puntaje morfológico total fueron notoriamente afectados por las tres concentraciones de misoprostol. Destacan entre estos, el pobre desarrollo de circulación del saco embrionario (Figuras $1 \mathrm{c}-\mathrm{d}$ ), barras braquiales, extremidades anteriores y posteriores y sistemas ótico y óptico, entre otros (Figuras 1 e-h). En la mayoría de los embriones, el corazón tenía una estructura irregular y la cabeza estaba pobremente desarrollada con un evidente retraso en la formación de romboencéfalo, mesencéfalo, prosencéfalo y tubo neural caudal, aumentado el las alteraciones y el retraso en el desarrollo, con la concentración de misoprostol.

Asimismo, se observó también una superficie embrionaria irregular, las que en algunos casos, contaban con alteración en la fusión del ectodermo distal (flechas blancas punteadas en las Figuras 1e y $1 \mathrm{~g}$ ). La rotación embrionaria fue también anormal, en especial en las porciones proximal y distal de los embriones (tres flechas negras juntas en las Figuras 1e-h). Las barras braquiales se presentaron deformadas y fusionadas, a tal punto que prácticamente no se desarrollaron a 2.000 y 20.000 $\mathrm{pg} / \mathrm{ml}$ (Figuras 1f-h). A estas concentraciones se observó además una fusión incompleta del tubo neural, fundamentalmente en su porción caudal.

\section{Discusión}

El misoprostol es un medicamento utilizado como abortivo. Tiene un porcentaje de falla de aproximadamente $15 \%$. Si el embarazo prosigue

Tabla 1. Parámetros morfométricos y sobrevivencia de embriones cultivados en presencia de concentraciones crecientes de misoprostola

\begin{tabular}{|lccccc|}
\hline $\begin{array}{l}\text { Concentración } \\
\text { de misoprostol } \\
\text { (pg/ml) }\end{array}$ & $\begin{array}{c}\text { Diámetro } \\
\mathbf{s a c o} \\
\mathbf{( m m}\end{array}$ & $\begin{array}{c}\text { Longitud } \\
\text { craneo-nalga } \\
\mathbf{( m m})\end{array}$ & $\begin{array}{c}\text { Longitud } \\
\text { cabeza } \\
\mathbf{( m m})\end{array}$ & $\begin{array}{c}\text { Puntaje } \\
\text { morfológico } \\
\text { total }\end{array}$ & $\begin{array}{c}\text { Sobrevivencia } \\
\text { (embriones vivos/ } \\
\text { embriones cultivados) }\end{array}$ \\
\hline 0 & $5,1 \pm 0,4$ & $3,3 \pm 0,3$ & $1,9 \pm 0,2$ & $57,5 \pm 3,3$ & $10 / 10$ \\
\hline $0+$ formamida & $4,8 \pm 0,2$ & $3,1 \pm 0,1$ & $1,9 \pm 0,1$ & $58,5 \pm 0,9$ & $10 / 10$ \\
\hline 200 & $4,8 \pm 0,2$ & $2,9 \pm 0,2^{*}$ & $1,7 \pm 0,1$ & $44,2 \pm 1,9^{*}$ & $9 / 10$ \\
\hline 2.000 & $4,4 \pm 0,1^{*}$ & $2,6 \pm 0,1^{*}$ & $1,6 \pm 0,1^{*}$ & $40,4 \pm 1,1^{*}$ & $9 / 10$ \\
\hline 20.000 & $4,1 \pm 0,1^{*}$ & $2,4 \pm 0,1^{*}$ & $1,4 \pm 0,2^{*}$ & $36,7 \pm 0,8^{*}$ & $7 / 10$ \\
\hline
\end{tabular}

${ }^{a}$ Datos se presentan como promedio \pm desviación estándar. *Valores estadísticamente distintos a tratamientos controles positivo y negativo $(p<0,0001)$. 


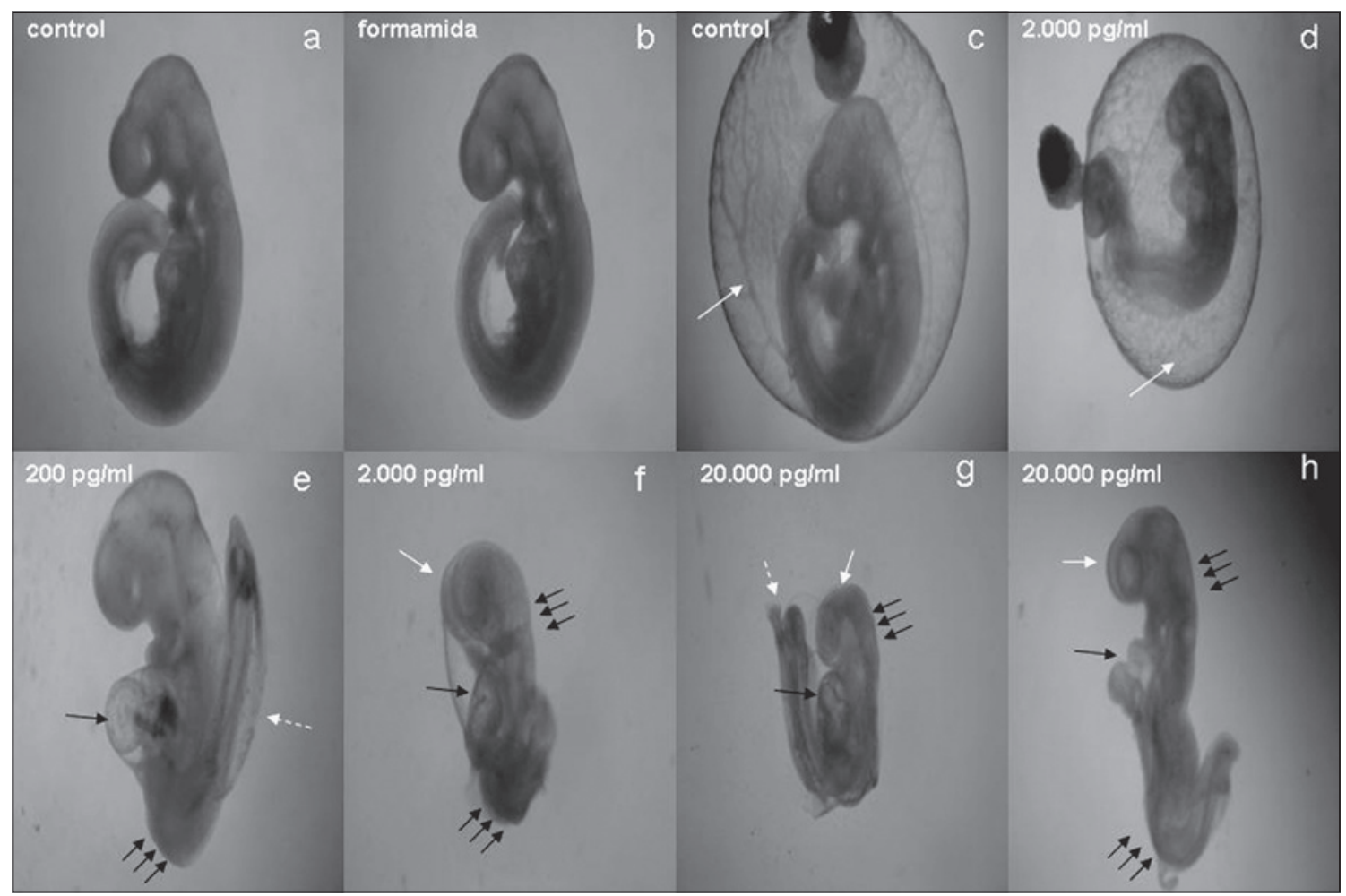

Figura 1. Embriones cultivados en presencia de misoprostol en concentraciones de 200, 2.000 y 20.000 pg/ml. a. Embrión control. b. Embrión en control de vehículo formamida. c-d. Embriones control y expuesto a misoprostol. Nótese las diferencias en el tamaño del embrión y del saco y en el desarrollo de la circulación vitelina (flechas blancas). e-h. Embriones expuestos a misoprostol. Flechas negras indican corazón malformado. Flechas blancas continuas indican alteración en la fusión del tubo neural. Flecha blanca punteada muestra falta de fusión ectodermo. Las tres flechas negras contiguas muestran alteración en la rotación embrionaria.

luego del intento de aborto fallido, existe un riesgo significativo de inducción de defectos congénitos. Sin embargo, prácticamente no existen en la literatura estudios con animales de experimentación que modelen la inducción de defectos del desarrollo observados en seres humanos e incluso los estudios llevados a cabo para evaluar al medicamento antes de su aprobación descartaron la teratogenicidad del compuesto ${ }^{7,8}$. Aun así, la asociación epidemiológica entre la exposición in utero al medicamento y la inducción de una serie de defectos incluyendo artrogriposis y síndrome de Moebius es fuerte e indicativa de un riesgo de inducción de defectos congénitos en humanos ${ }^{4}$ razón por la cual hemos buscado un modelo experimental que nos permita evaluar la inducción de dichos efectos.

El ensayo cultivo de embriones postimplantación es un ensayo reconocido como un método alternativo al estudio de toxicidad sobre la gesta- ción in vivo. Ha sido validado por la Comunidad Europea y se perfila como una buena herramienta para el estudio de teratógenos humanos. Una de sus ventajas es la ausencia de factores maternos, lo que permite estudiar el efecto directo sobre el embrión de la sustancia ensayada. Asimismo, este sistema permite la manipulación directa del embrión en las etapas de desarrollo de mayor susceptibilidad y por lo mismo, es de elección para estudiar mecanismos de acción de sustancias embriotóxicas ${ }^{13}$.

En humanos, el misoprostol es rápidamente desesterificado a ácido misoprostólico, su forma activa $^{14}$. La presencia y actividad de esterasas plasmáticas en el suero de rata ha sido extensamente avalado ${ }^{15}$, lo cual nos permitió modelar en nuestros cultivos la bioactivación de misoprostol, y aplicar este modelo para el estudio de la teratogenicidad del medicamento. 
Se ha señalado que misoprostol induciría daño embrionario a través de una hipoxia secundaria a las contracciones sostenidas del útero, las cuales podrían durar más de 24 horas, según lo señalado por mujeres que han seguido un procedimiento abortivo con el medicamento ${ }^{2}$. Por otro lado, Yip y $\mathrm{col}^{16}$, utilizaron ecografía Doppler para medir efectos vasoactivos en mujeres que tomaron 200 $\mu \mathrm{g}$ de misoprostol y confirmaron un aumento en la resistencia de la arteria uterina, lo cual implica una reducción en el flujo sanguíneo y concuerda con el mecanismo propuesto.

Contrario a este mecanismo, generalmente aceptado para la teratogenicidad del misoprostol, en el presente estudio hemos demostrado que embriones de ratas de 9,5 días cultivados por 48 horas en presencia de concentraciones crecientes de misoprostol, incluida aquella concentración que puede alcanzarse en el plasma de una mujer que ingiere el medicamento con fines abortivos, exhiben defectos del desarrollo demostrativos de embriotoxicidad y atribuibles a un efecto directo del medicamento sobre las estructuras embrionarias. Los defectos observados incluyen alteraciones en la viabilidad y funcionalidad embrionaria (pobre desarrollo vascular y sobrevivencia, entre otros) y morfometría (alteraciones en barras braquiales, corazón, porciones cefálicas del tubo neural, entre otros) siendo indicativos de la capacidad del medicamento de inducir no sólo retraso del desarrollo sino que también una alteración de éste. En otras palabras, estos resultados permiten proponer, que además del mecanismo indirecto de inducción de hipoxia embrionaria, el misoprostol podría también actuar directamente sobre el embrión. Sin embargo, dada las características del ensayo cultivo de embriones post-implantación (fundamentalmente la ausencia de factores maternos), éste no puede ser utilizado en reemplazo del estudio in vivo para la determinación de teratogenicidad ${ }^{17}$. Por lo mismo, se requiere de más estudios para poner a prueba esta hipótesis.

Agradecimientos: Las autoras agradecen a Silvana Flores, Yasna Baso, Romina Castillo y Andrea Tapia, estudiantes del Laboratorio de Toxicología, por el apoyo durante la realización de los experimentos.

\section{Referencias}

1. Hemmerling A. The safety of misoprostol. Intern J Gynecol Obstet 2006; 94 (S2): S149-50.

2. Faúndes A, Fiala C, Tang OS, Velasco A. Misoprostol for the termination of pregnancy up to 12 completed weeks of pregnancy. Intern J Gynecol Obstet 2007; 99: S172-7.

3. Schardein JL, Macina OT. Human Developmental Toxicants. Aspects of Toxicology and Chemistry. CRC Press, Boca Raton, 2007.

4. da Silva Dal Pizzol T, Pozzobon Knop F, Mengue SS. Prenatal exposure to misoprostol and congenital anomalies: Systematic review and meta-analysis. Reprod Toxicol 2006; 22: 666-71.

5. Los FJ, Brandenburg H, Niermeijer MF. Vascular disruptive syndromes after exposure to misoprostol or chorionic villus sampling. The Lancet 1996; 353: 843-4.

6. Webster WS, Abela D. The effect of hypoxia in development. Birth Def Res (Part C) 2007; 81: 215-28.

7. Kotsonis FN, Dodd DC, Regnier B, Kohn FE. Preclinical toxicology profile of misoprostol. Dig Dis Sci 1985; 30 (Suppl): 142S-6S.

8. Paumgarten FJR, Souza CAM, Carvalho RR, Chahoud I. Embryotoxic effects of misoprostol in the mouse. Braz J Med Biol Res 1995; 28: 355-61 (resumen).

9. National Academy of Sciences. Guide for the Care and Use of Laboratory Animals. National Academy Press, Washington DC, 1996.

10. Zieman M, Fong S, Benowitz N, Bankster D, Darney PD. Absorption kinetics of misoprostol with oral or vaginal administration. Obstet Gynecol 1997; 90: 88-92.

11. Khan R-U, El-Refaey H, Sharma S, Sooranna D, Stafford M. Oral, rectal, and vaginal pharmacokinetics of misoprostol. Obstet Gynecol 2004; 103: 866-70.

12. Brown NA, Fabro S. Quantitation of rat embryo development in vitro: A morphological scoring system. Teratology 1981; 24: 65-78.

13. Flick B y Klug S. Whole embryo culture: an important tool in developmental toxicology today. Curr Pharm Design 2006; 12: 1467-88.

14. Liederer BM, Borchardt RT. Enzymes involved in the bioconversion of ester-based prodrugs. J Pharm Sci 2006; 95: 1177-95.

15. Davies NM, Longstreth J, Jamali F. Misoprostol therapeutics revisited. Pharmacotherapy 2001; 21: 60-73.

16. Yip S-K, Tse A, Haines CJ, Chung T. Misoprostol's effect on uterine arterial blood flow and fetal heart rate in early pregnancy. Obstet Gynecol 2000; 95: 232-5.

17. Brent RL. Reproductive Toxicology. Reprod Toxicol 2010; 29: 251-3. 